\title{
Photobiocatalysis by a Lytic Polysaccharide Monooxygenase Using Intermittent Illumination
}

Blossom, Benedikt M.; Russo, David A.; Singh, Raushan K.; Van Oort, Bart; Keller, Malene B.; Simonsen, Tor; Perzon, Alixander; Gamon, Luke F.; Davies, Michael J.; Cannella, David; Croce, Roberta; Jensen, Poul Erik; Bjerrum, Morten J.; Felby, Claus

\section{Published in:}

ACS Sustainable Chemistry \& Engineering

DOI:

10.1021/acssuschemeng.0c00702

Publication date:

2020

Document version

Publisher's PDF, also known as Version of record

Document license:

$\mathrm{CC} B \mathrm{BY}$

Citation for published version (APA):

Blossom, B. M., Russo, D. A., Singh, R. K., Van Oort, B., Keller, M. B., Simonsen, T., Perzon, A., Gamon, L. F., Davies, M. J., Cannella, D., Croce, R., Jensen, P. E., Bjerrum, M. J., \& Felby, C. (2020). Photobiocatalysis by a Lytic Polysaccharide Monooxygenase Using Intermittent Illumination. ACS Sustainable Chemistry \&

Engineering, 8(25), 9301-9310. https://doi.org/10.1021/acssuschemeng.0c00702 


\section{Susstalinable Chemistry\& Engineering}

\section{Photobiocatalysis by a Lytic Polysaccharide Monooxygenase Using Intermittent Illumination}

Benedikt M. Blossom,* David A. Russo, Raushan K. Singh, Bart van Oort, Malene B. Keller, Tor I. Simonsen, Alixander Perzon, Luke F. Gamon, Michael J. Davies, David Cannella, Roberta Croce, Poul Erik Jensen, Morten J. Bjerrum, and Claus Felby*

Cite This: ACS Sustainable Chem. Eng. 2020, 8, 9301-9310

Read Online

\section{ACCESS \\ 山ll Metrics \& More \\ Article Recommendations \\ Supporting Information}

ABSTRACT: Photobiocatalysis holds great promise toward the development of sustainable and environmentally friendly processes, harnessing light to drive biocatalytic reactions. However, photobiocatalysis at the interface of insoluble substrates, such as cellulose, has not been studied in much detail. In this context, the catalytic enhancement of lytic polysaccharide monooxygenases (LPMOs) by light is of great interest to the biorefinery field due to their capacity to oxidatively cleave such recalcitrant polysaccharides which can facilitate the degradation of lignocellulose. It has previously been reported that light-driven LPMO reactions have a huge catalytic potential, but effective continuous illumination in reactors may be challenging. Therefore, we investigated the impact of intermittent illumination. We show that illumination intervals as short as $1 \mathrm{~s} / \mathrm{min}$ enable LPMO catalysis on phosphoric acid-swollen cellulose (PASC) to the same level as continuous illumination. Additionally, time-resolved measurements indicate that reductant depletion, and not enzyme inactivation, limits light-driven LPMO reactions. This study shows that a 60 -fold reduction in illumination time enhances LPMO catalysis while protecting reaction elements, e.g., the reductant. Most importantly, the significant enhancement of LPMO catalysis with minimal and intermittent illumination is promising toward an application of photobiocatalytic depolymerization of lignocellulose where shading and light scattering minimize light availability and continuity.

KEYWORDS: Photobiocatalysis, Lytic polysaccharide monooxygenases, Cellulose oxidation, Intermittent light, Reactive oxygen species (ROS), Photosensitizer, Chlorophyllin

\section{INTRODUCTION}

In recent years, photobiocatalysis has been established as a promising field of research aiming at delivering green solutions for a much needed transition into a sustainable future. ${ }^{1}$ Essentially, it combines the better of two worlds, namely, photocatalysis and biocatalysis, to drive enzymatic reactions by light under conditions that are environmentally favorable. Various redox enzymes, such as cytochrome P450s or laccases, have been successfully tested for their potential to be applied in such systems. ${ }^{2-6}$ Among the tested combinations, photobiocatalysis at the interface of water-insoluble biopolymers, such as cellulose, has not received detailed attention. It presents a particular challenge as the biocatalyst is water soluble and is required to bind onto and attack a densely packed polymeric substrate. Here, lytic polysaccharide monooxygenases (LPMOs) are "the weapon of choice" because the rather unique architecture of the active site of these mono-copper enzymes, in which the copper is coordinated by a histidine brace, allows for interaction with crystalline and recalcitrant polysaccharides. ${ }^{7-10}$ In this context, a novel and promising photoactivation approach for the degradation of plant waste material has been outlined recently which showed that light-driven systems, composed of a photosensitizer and a reductant, could dramatically increase LPMO activity. ${ }^{11,12}$ It has furthermore been suggested that this activity enhancement is due to light-driven $\mathrm{H}_{2} \mathrm{O}_{2}$ formation. ${ }^{13}$ While the full mechanism behind the light-driven formation of $\mathrm{H}_{2} \mathrm{O}_{2}$ and LPMO activation has not been resolved yet, the current disadvantage of such a light-driven system is that besides activating the LPMO excess $\mathrm{H}_{2} \mathrm{O}_{2}$ can be detrimental to both photosensitizer and enzyme. ${ }^{14}$

However, LPMOs have become an essential part of industrial enzyme cocktails for lignocellulose transformation, generating fermentable sugars for conversion to fuels and chemicals due to their synergistic mode of action with canonical cellulases. ${ }^{15,16}$ The products of LPMO catalysis are oxidized oligosaccharides and their nonoxidized counterparts. In glucans, the oxidation of the pyranose ring can take place at

Received: January 27, 2020

Revised: $\quad$ May 7, 2020

Published: May 21, 2020 
the $\mathrm{C} 1$ position, producing aldonic acids, or at the $\mathrm{C} 4$ position, producing 4-ketoaldose (gemdiols). ${ }^{17,18}$ Regardless of the type of oxidation and cosubstrate $\left(\mathrm{O}_{2}\right.$ or $\left.\mathrm{H}_{2} \mathrm{O}_{2}\right)$, the copper ion in the active site of the LPMO binds an activated oxygen species which is the active component in the oxidation. ${ }^{14,19,20}$ The exact nature of the activated oxygen species involved in LPMO catalysis still remains unresolved and is widely discussed. Interestingly, emerging evidence has shown that when LPMOs of the family AA9 use $\mathrm{H}_{2} \mathrm{O}_{2}$ as the cosubstrate, a Cu-tyrosyl radical can be formed which possibly serves to protect the protein-active site from inactivation during uncoupled turnover. $^{21,22}$ If no carbohydrate substrate is present, LPMOs are known to perform a "futile cycle", producing $\mathrm{H}_{2} \mathrm{O}_{2}$, which can eventually inactivate the enzyme due to oxidative damage to the copper-coordinating histidines at the active site. ${ }^{14,23}$ As part of the catalytic cycle, an external electron donor is needed to reduce the copper at the active site from $\mathrm{Cu}^{2+}$ to $\mathrm{Cu}^{+}$, which can be from a wide range of sources ranging from phenolic compounds to organic acids and has been found to have a strong impact on the reactivity of LPMOs. ${ }^{24,25}$ Harnessing the energy of the sun to drive such biochemical processes is an intriguing concept that opens up a wide range of perspectives for future biotechnological applications, possibly expanding the use of LPMOs into areas other than cellulosic biofuels. ${ }^{26}$ However, due to the high optical density of lignocellulose substrates as well as potential damage to the enzymes from excessive ROS formation, effective continuous application of light in current reactor designs imposes a challenge. Therefore, alternative reactor designs or methods for light applications may be necessary. With the aim of optimizing light delivery, we investigated the effect of constant and intermittent illumination on light-driven LPMO-catalyzed oxidation of cellulose substrates and how this affects the level of cellulose oxidation and the formation of $\mathrm{H}_{2} \mathrm{O}_{2}$ within the system. Our results provide a basis upon which novel photobioreactors for biomass oxidation can be designed.

\section{EXPERIMENTAL SECTION}

LPMO Purification and Copper Loading. Thielavia terrestris LPMO (TtAA9, previously TtGH61) was provided as a broth from Novozymes A/S (Denmark). In order to achieve full copper loading of the enzyme, the TtAA9 was saturated with $\mathrm{Cu}(\mathrm{I})$ chloride under anaerobic conditions and on ice for $2 \mathrm{~h}$.

This preparation was then filtered and subsequently injected into an ÄKTA chromatography system (Amersham Pharmacia Biotech, Sweden) equipped with a Hiload 26/60 Superdex 75 prep grade column (Pharmacia Biotech) and equilibrated with $20 \mathrm{mM}$ MOPS buffer (pH 7.0). HoloTtAA9 (i.e., copper-loaded TtAA9 and hereafter TtAA9) eluted in a single peak using $20 \mathrm{mM}$ MOPS buffer ( $\mathrm{pH} 7.0$ ) with a flow rate of $1 \mathrm{~mL} \mathrm{~min}{ }^{-1}$. The single peak fractions were then combined and concentrated with an Amicon Ultra- 15 centrifugal filter ( $3 \mathrm{kDa}$, Merck Millipore Ltd. Ireland) and kept at $4{ }^{\circ} \mathrm{C}$ until further use. The purity of the HoloTtAA9 preparation was tested for by sodium dodecyl sulfate-polyacrylamide gel electrophoresis (SDSPAGE) with a mini-PROTEAN TGX precast gel from Bio-Rad Laboratories with a gradient of $4 \%-15 \%$. The protein bands were stained with Coomassie blue, and the mass was determined by Precision Plus Protein Standards.

To determine the copper content of the TtAA9, high resolution inductively coupled plasma-MS (ICP-MS) was used (Aurora M90 ICP-MS system Bruker, Germany), and the corresponding data were collected using Bruker Quantum software. Optimization parameters for plasma flow, auxiliary flow, sheath gas and nebulizer flow were $16.5,2.0,0.2$, and $1.0 \mathrm{~L} \mathrm{~min}^{-1}$, respectively.
A standard curve was generated from known concentrations $(0-50$ $\mu \mathrm{g} \mathrm{L}^{-1}$ ) of an internal standard solution (IV-ICPMS-71A solution, Inorganic ventures, Christiansburg, VA, USA) to determine the metal content by comparison of the sample to the standard curve. After instrument calibration, $2 \%$ nitric acid was used as a control before running protein samples, and the TtAA9 preparations (1-2 mg $\mathrm{mL}^{-1}$ ) were diluted as necessary in $2 \%$ nitric acid. An average of three analyses of each sample was taken.

Protein concentrations of purified TtAA9 were estimated based on its absorbance at $280 \mathrm{~nm}$ using a NanoDrop spectrophotometer (Fisher Scientific, USA). The TtAA9 sequence was used to calculate the extinction coefficient of the TtAA9 $\left(\varepsilon 280=58,120 \mathrm{M}^{-1} \mathrm{~cm}^{-1}\right)$ with an online tool available at https://web.expasy.org/protparam $/ .^{27}$

Reagents. Ascorbic acid was obtained from Sigma-Aldrich (St. Louis, MO, USA). Stock solutions of $100 \mathrm{mM}$ were prepared in MQ water and kept at $-20{ }^{\circ} \mathrm{C}$ in the dark until use.

Substrates. Microcrystalline cellulose (Avicel, PH-101) was obtained from Sigma-Aldrich.

Phosphoric acid-swollen cellulose (PASC) was prepared by treating microcrystalline cellulose (Avicel $\mathrm{PH}-101$ ) with phosphoric acid as previously described. ${ }^{28}$ Briefly, $4 \mathrm{~g}$ of Avicel PH-101 was dispersed into $100 \mathrm{~mL}$ of phosphoric acid $(86 \% \mathrm{w} / \mathrm{v})$ at $60{ }^{\circ} \mathrm{C}$ and magnetically stirred for an hour. Then, $1900 \mathrm{~mL}$ of $\mathrm{H}_{2} \mathrm{O}$ was slowly dripped into the solution while stirring. The suspension was then allowed to form sediment at $4{ }^{\circ} \mathrm{C}$. After sedimentation, the supernatant was removed. The suspension was washed four times with $\mathrm{H}_{2} \mathrm{O}$, and the $\mathrm{pH}$ was neutralized using $\mathrm{Na}_{2} \mathrm{CO}_{3}$.

Preparation of Cellulose Nanofibrils (CNF). Destarched pulp from potato tubers $\left(20 \mathrm{~g}\right.$ dry weight) was washed with $15 \mathrm{~L} \mathrm{H}_{2} \mathrm{O}$ on a sieve (pore size $38 \mu \mathrm{m}$ ) to remove the remaining starch granules and water-soluble compounds. The washed pulp was then soaked in 500 $\mathrm{mL}$ of $0.5 \mathrm{M} \mathrm{NaOH}$ and heated to $80{ }^{\circ} \mathrm{C}$ under stirring for $2 \mathrm{~h}$ to remove hemicelluloses and pectin. The treatment was repeated once more by collecting the wet pulp on a sieve and transferring it to a fresh solution of $0.5 \mathrm{M} \mathrm{NaOH}$. After $2 \mathrm{~h}$ of stirring at $80^{\circ} \mathrm{C}$, the pulp was washed with distilled water until neutral $\mathrm{pH}$ was reached. Subsequently, the pulp was suspended in $500 \mathrm{~mL}$ of $\mathrm{NaClO}$ solution $(1 \% \mathrm{v} / \mathrm{v}, \mathrm{pH} 5.0)$ to oxidize lignin and tannins, as well as introducing carboxyl groups onto cellulose. The oxidation with $\mathrm{NaClO}$ was carried out at $70{ }^{\circ} \mathrm{C}$ under mixing for $2 \mathrm{~h}$, where after the cellulose fibers were washed extensively with distilled water. The cellulose fibers were finally diluted to $0.9 \%(\mathrm{w} / \mathrm{w})$ in distilled water and passed through a high-shear homogenizer (microfluidizer materials processor M110-P with orifices of 200 and $400 \mu \mathrm{m}$ ) under a pressure of $500 \mathrm{bar}$ for $18 \mathrm{~min}$ to produce nanofibrils. The resulting transparent nanofibril suspension was stored at $4{ }^{\circ} \mathrm{C}$.

Photosensitizer. Chlorophyllin (product code C-100.000-WS-P) produced by extraction of Festuca arundinacae was a gift from Chr. Hansen, Hørsholm, Denmark. The final concentration (mM) of chlorophyllin was determined based on an average molar mass of $724.15 \mathrm{~g} \mathrm{~mol}^{-1}$.

Protein Oxidation Measurements. Protein samples $(20 \mu \mathrm{g})$ were precipitated with trichloroacetic acid (TCA) (final concentration $\mathrm{w} / \mathrm{v} 10 \%$ ) and spiked with a mix of 17 stable isotope-labeled amino acid standards $(250 \mathrm{pmol}$ each with the exception of cysteine at 125 pmol) before evaporation using a centrifugal vacuum concentrator for $15 \mathrm{~min}$. The resulting pellet was hydrolyzed for $16 \mathrm{~h}$ in $4 \mathrm{M}$ methanesulfonic acid (MSA) with $0.2 \%$ tryptamine $(50 \mu \mathrm{L})$ under vacuum at $110^{\circ} \mathrm{C}$. Amino acids were partially purified by solid-phase extraction using $30 \mathrm{mg} \mathrm{mL}^{-1}$ mixed mode strong cation exchange Strata X-C cartridges (Phenomenex). The columns were activated using $100 \%$ methanol $(1 \mathrm{~mL})$, followed by equilibration with $0.1 \%$ formic acid (FA) in $\mathrm{H}_{2} \mathrm{O}(1 \mathrm{~mL})$. Samples were diluted with $0.1 \%$ formic acid in $\mathrm{H}_{2} \mathrm{O}(10 \mu \mathrm{L}$ hydrolysate into $990 \mu \mathrm{L}$ of $0.1 \% \mathrm{FA})$ to reduce competitive binding with MSA in the sample matrix. The samples were loaded onto the column and washed with $0.1 \% \mathrm{FA}$ in $\mathrm{H}_{2} \mathrm{O}(1 \times 0.6 \mathrm{~mL})$ and $0.1 \%$ FA in acetonitrile $(1 \times 0.6 \mathrm{~mL})$ followed by elution with $20 \%$ acetonitrile in $1 \%$ aqueous ammonium hydroxide $(1 \times 0.6 \mathrm{~mL})$. Extracts were dried at $60^{\circ} \mathrm{C}$ under vacuum for $4 \mathrm{~h}$ and dissolved in $50 \mu \mathrm{L}$ of $0.1 \%$ FA. Polar amino acids were eluted during 
the washing steps, while more hydrophobic amino acids such as histidine, lysine, arginine, tyrosine, and tryptophan were quantified in the eluted extracts.

Parent amino acids were quantified by ESI LC-MS in the positive ion mode using a Bruker Impact HD II mass spectrometer. Samples were separated by gradient elution using an Imtakt Intrada Amino Acid $100 \mathrm{~mm} \times 3.0 \mathrm{~mm}$ column using acetonitrile/formic acid (Solvent A; 99.7/0.3) and acetonitrile/100 mM ammonium formate (Solvent B; 20/80). The elution was initiated at $20 \%$ B for $4 \mathrm{~min}$, followed by gradient elution from $20 \%$ to $100 \%$ B over $10 \mathrm{~min}, 100 \%$ B over $2 \mathrm{~min}$, before decreasing to $20 \% \mathrm{~B}$ over $2 \mathrm{~min}$ and reequilibration at $20 \%$ B for $2 \mathrm{~min}$. The electrospray needle was held at $4500 \mathrm{~V}$ with end plate offset of $500 \mathrm{~V}$ and a temperature of $350{ }^{\circ} \mathrm{C}$. Nitrogen gas was used for both the nebulizer ( 2 bar) and as the dry gas $\left(11 \mathrm{~L} \mathrm{~min}^{-1}\right)$. The amino acid standard curves were generated with a concentration range of $2-500$ pmol loaded onto the column, with the internal standards maintained at a loading of 100 pmol. Standards were prepared in $0.1 \%$ formic acid in $\mathrm{H}_{2} \mathrm{O}$. Spectra were collected in MS1 mode and quantification performed on extracted ion chromatograms, e.g., histidine $(m / z=156.0773 \pm 0.01)$ and $[13 \mathrm{C} 6$, $15 \mathrm{~N} 3]$ histidine $(\mathrm{m} / z=165.0883 \pm 0.01)$. The mix of isotopically labeled standards (MSK-A2-1.2) was purchased from Cambridge Isotope Laboratories. All solvents were LCMS grade (VWR). Standard curves ranging from 2 to 1000 pmol native His yielded a linear correlation with $\mathrm{R}^{2}=0.9975$.

LPMO Binding Measurements. Avicel suspensions in $100 \mathrm{mM}$ citrate buffer $\mathrm{pH} 6.0$ were added to a 96-well microtiter plate in varying final loads between 0 and $150 \mathrm{~g} \mathrm{~L}^{-1}$. The samples were incubated with $600 \mathrm{nM}$ TtAA9 and $2 \mathrm{mM}$ ascorbic acid in an Eppendorf Thermomixer at $800 \mathrm{rpm}$ for an hour at $50{ }^{\circ} \mathrm{C}$. The samples were subsequently centrifuged for $3 \mathrm{~min}$ at $3000 \mathrm{rpm}$, and $100 \mu \mathrm{L}$ of the supernatant was added to a black 96-well microtiter plate. The protein concentrations of unbound TtAA9 in the samples were determined by intrinsic fluorescence at $345 \mathrm{~nm}$ in a plate reader (Molecular Devices SpectraMax i3) using an excitation wavelength of $280 \mathrm{~nm}$. Standard curves ranged from 0 to $600 \mathrm{nM}$ TtAA9, with 2 $\mathrm{mM}$ ascorbic acid in $100 \mathrm{mM}$ citrate buffer $\mathrm{pH} 6.0$ yielded a linear correlation with an $\mathrm{R}^{2}$ value of 0.989 . All experiments were performed in triplicates.

High Performance Anion-Exchange Chromatography (HPAEC) Analysis and Quantification of Products. After each LPMO activity assay, the samples were diluted in $50 \mathrm{mM}$ sodiumcitrate buffer ( $\mathrm{pH} 5.0$ ), vortexed, and then centrifuged at 13,000 rpm for $3 \mathrm{~min}$. The supernatant was transferred into a fresh tube and divided into two fractions for either direct high performance anionexchange chromatography (HPAEC) analysis or subsequent hydrolysis by a beta-glucosidase from Aspergillus niger (Megazyme, Ireland) for the quantification of the C1-specific LPMO oxidation product, i.e., gluconic acid by HPAEC analysis as described by Keller et al. ${ }^{29}$

The measurement of polysaccharide oligomers by HPAEC was performed on an ICS 5000+ system, equipped with a PAD detector (Thermo Scientific), a CarboPac PAl column $(2 \mathrm{~mm} \times 50 \mathrm{~mm}$ guard column, an additional NG1 guard column, and followed by a $2 \mathrm{~mm} \times$ $250 \mathrm{~mm}$ analytical column), and operated at a flow of $0.25 \mathrm{~mL} \mathrm{~min}^{-1}$ at $30^{\circ} \mathrm{C}$. Chromatographic analysis of aldonic acid was conducted as described by Westereng et al. ${ }^{30}$ The elution involved a linear gradient from $100 \%$ A:0\% B to $90 \%$ A: $10 \%$ B (10 min), followed by an exponential gradient to $70 \%$ A:30\% B (15 min), and last an exponential gradient to $100 \%$ B ( $5 \mathrm{~min}$ ). After that, a linear gradient was applied for $15 \mathrm{~min}$ at the initial conditions of $100 \% \mathrm{~A}: 0 \% \mathrm{~B}$ (eluent A: $0.1 \mathrm{M} \mathrm{NaOH}$, eluent B: $0.1 \mathrm{M} \mathrm{NaOH}$ and $1 \mathrm{M} \mathrm{NaOAc}$ ). The cellulose oligomers in the chromatograms are assigned according to the elution time of commercially available nonoxidized oligosaccharide standards and oxidized standards generated by a base-catalyzed oxidation reaction with iodine, using the approach described elsewhere for cellobiose. ${ }^{31}$ The data presented here are the average of three replicates unless otherwise stated. The statistical analyses to determine significant differences between the means of incubations were performed by one-way ANOVA in combination with Tukey's HSD posthoc test for multiple comparisons. Differences were deemed significant for $\mathrm{p}$-values $<0.05$.

Oxygen Measurements. The oxygen consumption was measured at room temperature with a Chlorolab 2 System (Hansatech, England), with an oxygen sensor mounted at the bottom of a sealed reaction chamber. The content of the reaction chamber $(1.5 \mathrm{~mL})$ was stirred by a magnet and was equipped with a window for light exposure. The incubations consisted of $2 \mathrm{mM}$ ascorbic acid, $0.8 \mathrm{mM}$ chlorophyllin in a citrate buffer $(100 \mathrm{mM}, \mathrm{pH} 6.0)$, and for comparison, TtAA9 $(2 \mu \mathrm{M})$ and $0.5 \% \mathrm{w} / \mathrm{v}$ PASC were added, resembling the light-activated LPMO system (full assay). The reactants were added from the start, and the subsequent oxygen consumption measurements were detected in $\mathrm{nmol} \mathrm{ml}^{-1}$ and monitored for $30 \mathrm{~min}$. Constant illumination was provided with an intensity of $200 \mu \mathrm{mol}$ photons $\mathrm{m}^{-2} \mathrm{~s}^{-1}(625 \mathrm{~nm})$. The catalasecoupled $\mathrm{H}_{2} \mathrm{O}_{2}$ detection assay was performed as the oxygen consumption measurements except for the addition of catalase after $30 \mathrm{~min}$ of incubation. Upon catalase addition, the oxygen evolution was measured and compared to a hydrogen peroxide/oxygen evolution standard curve to calculate the amount of free $\mathrm{H}_{2} \mathrm{O}_{2}$ in the incubations.

It is important to note that using the $10 \mathrm{~s} \mathrm{~min}^{-1}$ illumination cycle the oxygen chamber had to be entirely filled with sample and sealed to avoid oxygen diffusion into the chamber during the measurements in order to detect any oxygen consumption (data not shown).

Experimental Conditions (Photobiocatalysis). Unless otherwise stated, all photobiocatalytic incubations were composed of 0.8 $\mathrm{mM}$ chlorophyllin, $2 \mathrm{mM}$ ascorbic acid, $2 \mu \mathrm{M}$ purified and copper saturated TtAA9 in $100 \mathrm{mM}$ citric acid buffer ( $\mathrm{pH}$ 6.0), a reaction volume of $300 \mu \mathrm{L}$, and incubated in reaction tubes at $50{ }^{\circ} \mathrm{C}$ on a thermomixer at $600 \mathrm{rpm}$ illuminated from the top with white LEDs $\left(200 \mu \mathrm{mol}\right.$ photons $\left.\mathrm{m}^{-2} \mathrm{~s}^{-1}\right)$.

For PASC, the substrate loading was $0.5 \%(\mathrm{w} / \mathrm{v})$. Microcrystalline cellulose (Avicel) was applied in various substrate loadings $0.1 \%-15 \%$ $(\mathrm{w} / \mathrm{v})$, and for cellulose nanofibrils, $0.25 \%(\mathrm{w} / \mathrm{v})$ was used (unless stated otherwise).

The incubation time was $3 \mathrm{~h}$ except for time-course experiments. For all experiments, $200 \mu \mathrm{mol}$ photons $\mathrm{m}^{-2} \mathrm{~s}^{-1}$ from white LEDs were used for illumination of the samples. The spectral output of the white LEDs can be found in the Supporting Information (Figure S1). Illumination was either continuous or intermittent. Intermittent illumination consisted of a sequence of periods with ( 1 or $10 \mathrm{~s})$ and without ( 59 or $50 \mathrm{~s}$ ) illumination, which are indicated as 1 and $10 \mathrm{~s} /$ min, respectively.

Optical Spectroscopy. Optical transmittance spectra were measured on a SpectraMax i3 plate reader (Molecular Devices) with spectral fusion illumination and a horizontal optical path length of $1 \mathrm{~cm}$ using 96-well plates. Samples were vigorously mixed immediately before the recording of each spectrum.

\section{RESULTS AND DISCUSSION}

In this study, we investigated the effect of intermittent illumination, as opposed to constant illumination, in a lightdriven system for LPMO catalysis. This has the potential to increase the robustness of light-driven enzyme catalysis by reducing formation of ROS in the system as well as to advance the design of photobioreactors. We used a C1-oxidizing LPMO from Thielavia terrestris (TtAA9) in combination with the chlorophyllin/ascorbic acid system ${ }^{11}$ activated by either intermittent light (10 or $1 \mathrm{~s} / \mathrm{min}$ illumination cycles) or constant light. The carbohydrate substrates were phosphoric acid-swollen cellulose (PASC), microcrystalline cellulose (Avicel), and cellulose nanofibrils (CNF), and their oxidation products were analyzed and quantified by HPAEC-PAD. We ultimately show that it is possible to reduce illumination time up to 60 -fold while still maintaining similar polysaccharide oxidation levels. 
A

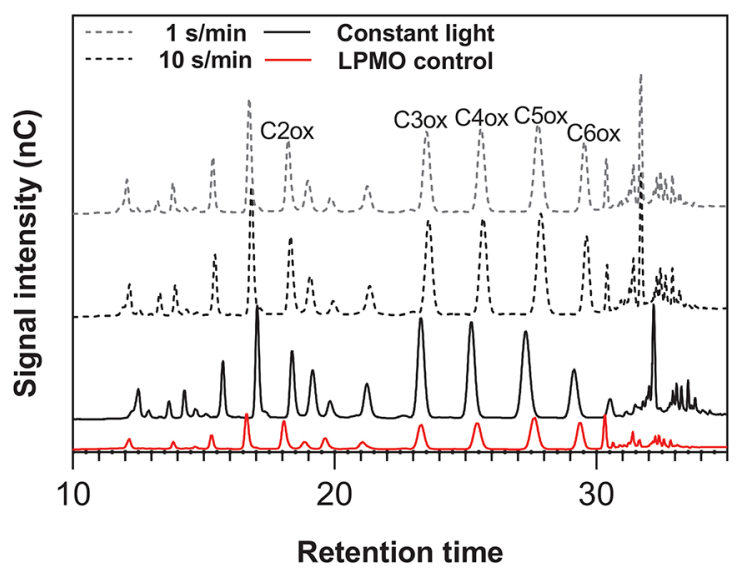

B

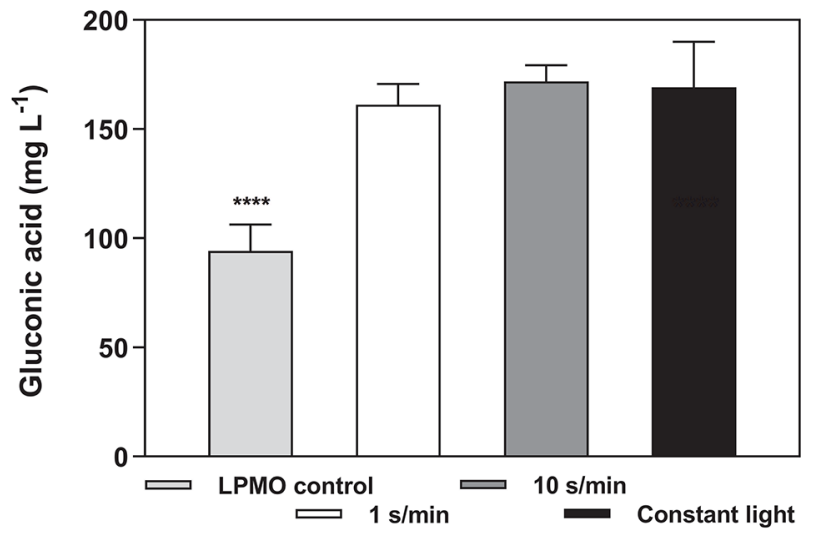

Figure 1. PASC oxidation and product formation by light-driven LPMO catalysis. Here, $0.5 \%$ PASC was incubated for $3 \mathrm{~h}$ with constant, $10 \mathrm{~s} / \mathrm{min}$, and $1 \mathrm{~s} / \mathrm{min}$ illumination under standard light-driven reaction conditions $(0.8 \mathrm{mM}$ chlorophyllin, $2 \mathrm{mM}$ ascorbic acid, $2 \mu \mathrm{M}$ TtAA9, in $100 \mathrm{mM}$ citrate buffer ( $\mathrm{pH} 6.0$ ), $200 \mu \mathrm{mol}$ photons $\mathrm{m}^{-2} \mathrm{~s}^{-1}, 50{ }^{\circ} \mathrm{C}$, and $600 \mathrm{rpm}$ ). In addition, a control reaction was performed of the same composition but in the dark and omitting chlorophyllin (LPMO control). (A) HPAEC-PAD chromatograms after incubations under different light regimes: $1 \mathrm{~s} /$ min (dashed light gray line), $10 \mathrm{~s} / \mathrm{min}$ (dashed black line), constant light (solid black line), and LPMO control (red line). The peaks were annotated according to the retention time of oxidized oligosaccharide standards. C2ox, cellobionic acid; C3ox, cellotrionic acid; C4ox, cellotetraonic acid; C5ox, cellopentaonic acid; C6ox, cellohexaonic acid. (B) Gluconic acid quantification of soluble fraction. Illumination was constant (black), $10 \mathrm{~s}$ light $\mathrm{min}^{-1}$ (dark gray), or $1 \mathrm{~s}$ light $\mathrm{min}^{-1}$ (white). The LPMO control was incubated in the dark and omitted chlorophyllin (light gray). The error bars represent the standard deviation of six sample replicates. $* * * *$ indicates significant differences.

Intermittent Light Cycles Dramatically Reduce Energy Input in Light-Driven LPMO Reactions. To initially investigate the effect of intermittent illumination, PASC was used as an easily accessible substrate, i.e., a substrate with low recalcitrance, in order to minimize the influence of noncatalytic side reactions (e.g., futile cycle). ${ }^{23}$ We incubated PASC for $3 \mathrm{~h}$ and exposed the photobiocatalytic system to either constant or intermittent illumination (both 10 and $1 \mathrm{~s} / \mathrm{min}$ ), and as an activity control, we incubated samples of the same composition but without photosensitizer in the dark. Surprisingly, the analysis of the reaction products by HPAEC-PAD showed no visible difference in the chromatograms between constant, 10 $\mathrm{s} / \mathrm{min}$, and $1 \mathrm{~s} / \mathrm{min}$ illumination (Figure $1 \mathrm{~A}$ ). The subsequent quantification of released and soluble oligosaccharides supported this observation. The average gluconic acid (GlcA) formation was not significantly different with constant $\left(166 \mathrm{mg} \mathrm{L}^{-1}\right), 1 \mathrm{~s} / \mathrm{min}\left(161 \mathrm{mg} \mathrm{L}^{-1}\right)$, and $10 \mathrm{~s} / \mathrm{min}(172 \mathrm{mg}$ $\mathrm{L}^{-1}$ ) illumination but was significant compared to the dark control (94 $\left.\mathrm{mg} \mathrm{L}^{-1}\right)$ (Figure 1B). The difference between light and dark incubations was further investigated in an additional experiment which revealed that using the light-driven LPMO assay on PASC the LPMO enzyme load could be reduced 4fold to reach the same GlcA concentration compared to the ascorbic acid-driven LPMO reaction (Figure S2).

Overall, the results demonstrate that light-driven LPMO catalysis with intermittent illumination can efficiently oxidize a highly amorphous cellulosic substrate, such as PASC, with reduced light input. It is important to note that the hereapplied light intensities are several orders of magnitude lower compared to the light intensities reported in a recent study. ${ }^{13}$ The possibility to drastically reduce the light input in this lightdriven system without reducing the biocatalytic outcome underlines the importance of carefully controlling the illumination input in order to ensure LPMO-specific catalysis to avoid ROS-mediated side reactions and noncontrolled photochemical reactions, e.g., photodegradation of the applied photosensitizers, that are likely to occur under high-light conditions. Furthermore, the capacity to achieve a significant enhancement of LPMO catalysis with minimal light input may be a benefit toward the design of photobioreactors, where shading, light scattering, and absorption by nonphotosensitizing molecules reduce the light available to drive photobiocatalytic reactions.

Extended Illumination Is Required to Efficiently Oxidize Higher Avicel Loadings. To elucidate the influence of substrate recalcitrance and substrate loading, microcrystalline cellulose (Avicel) ranging from 10 to $150 \mathrm{~g} \mathrm{~L}^{-1}$ was incubated for $3 \mathrm{~h}$ with the light-driven LPMO assay with $1 \mathrm{~s} /$ $\mathrm{min}, 10 \mathrm{~s} / \mathrm{min}$, and constant illumination (Figure 2). At low

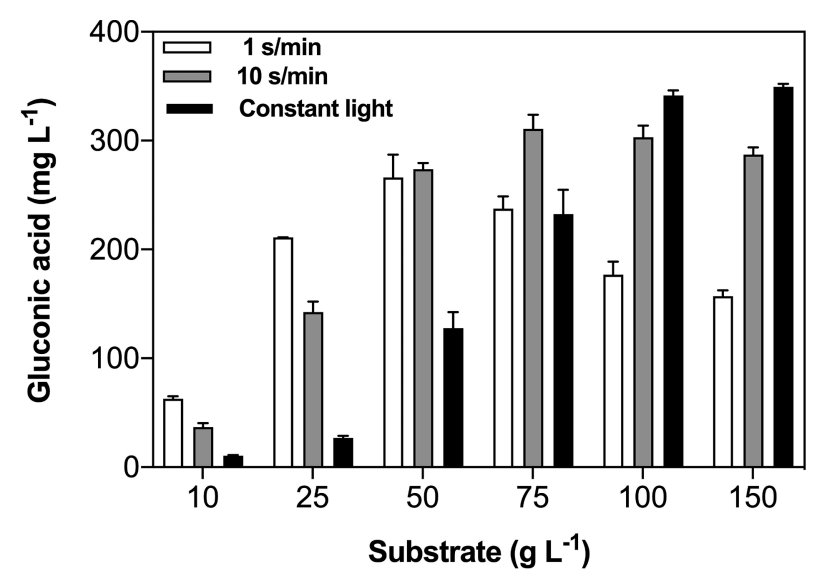

Figure 2. Light-driven LPMO catalysis for the oxidation of microcrystalline cellulose at various loadings. Microcrystalline cellulose (Avicel) was applied at substrate loadings ranging from 10 to $150 \mathrm{~g} \mathrm{~L}^{-1}$ and incubated under standard conditions $(0.8 \mathrm{mM}$ chlorophyllin, $2 \mathrm{mM}$ ascorbic acid, $2 \mu \mathrm{M}$ TtAA9, in $100 \mathrm{mM}$ citrate buffer (pH 6.0), $3 \mathrm{~h}, 200 \mu \mathrm{mol}$ photons $\mathrm{m}^{-2} \mathrm{~s}^{-1}, 50{ }^{\circ} \mathrm{C}$, and 600 $\mathrm{rpm})$. Illumination was constant (black), $10 \mathrm{~s}$ light $\mathrm{min}^{-1}$ (dark gray), or $1 \mathrm{~s}$ light $\mathrm{min}^{-1}$ (white). The error bars represent the standard deviation of three replicates. 
substrate loadings (10 and $\left.25 \mathrm{~g} \mathrm{~L}^{-1}\right), 1 \mathrm{~s} / \mathrm{min}$ illumination yielded a significantly higher GlcA concentration than $10 \mathrm{~s} /$ min illumination or constant light (Figure 2). At $50 \mathrm{~g} \mathrm{~L}^{-1}$ Avicel, the GlcA yield was almost equal for the 1 and $10 \mathrm{~s} / \mathrm{min}$ illuminations (266 and $274 \mathrm{mg} \mathrm{L}^{-1}$ GlcA, respectively) but significantly lower under constant illumination $\left(128 \mathrm{mg} \mathrm{L}^{-1}\right.$ GlcA). Raising the substrate loadings further (to $75 \mathrm{~g} \mathrm{~L}^{-1}$ ) increased the GlcA yield for $10 \mathrm{~s} / \mathrm{min}$ and constant illumination with significant differences between the two, with the highest level of GlcA for $10 \mathrm{~s} / \mathrm{min}$, but the yield decreased for $1 \mathrm{~s} / \mathrm{min}$ illumination. At substrate loadings of 100 and $150 \mathrm{~g} \mathrm{~L}^{-1}(\mathrm{w} / \mathrm{v})$, the GlcA yield was significantly higher under constant illumination, with a small decrease for the $10 \mathrm{~s} / \mathrm{min}$-cycle and a larger decrease for $1 \mathrm{~s} / \mathrm{min}$.

These results suggest a correlation between substrate loading and optimal illumination time for maximum substrate oxidation; that is, with increasing substrate loadings, a longer illumination time is needed to maximize the product yield. At substrate loadings up to $50 \mathrm{~g} \mathrm{~L}^{-1}$ Avicel, a 60 -fold reduced illumination time $(1 \mathrm{~s} / \mathrm{min})$ was the most efficient to drive LPMO catalysis, yielding 8-fold more product compared to constant illumination at $25 \mathrm{~g} \mathrm{~L}^{-1}$. However, increasing the substrate load further to $75 \mathrm{~g} \mathrm{~L}^{-1}$ Avicel showed that an extended illumination time $(10 \mathrm{~s} / \mathrm{min})$ was required to generate higher product concentrations, and at the highest substrate loadings (100 and $150 \mathrm{~g} \mathrm{~L}^{-1}$ Avicel), constant illumination was needed to maximize the product yield.

The requirement for longer illumination times with increasing substrate loadings may be explained by diminished light penetration into the system and light absorption by the photosensitizer. With increasing Avicel loadings, light transmittance rapidly decreased from $50 \%$ at $1 \mathrm{~g} \mathrm{~L}^{-1}(\mathrm{w} / \mathrm{v})$ to $0.6 \%$ at $100 \mathrm{~g} \mathrm{~L}^{-1}(\mathrm{w} / \mathrm{v})$ (Figure S3). The shape of the transmittance spectrum indicates that the transmittance loss is mainly due to scattering and not due to absorbance of light by the substrate (note that the substrate particle size is approximately $50 \mu \mathrm{m}$ ). To some degree, the scattering will be directed outward of the sample which will inevitably reduce the amount of absorbed light by the photosensitizer. Therefore, in order to achieve an equal amount of light absorption (and hence product yield), it is necessary to steadily extend the illumination time with increasing substrate loadings of microcrystalline cellulose.

In contrast, extended illumination at lower substrate loadings reduces product yield. This may be due to a reduced ratio of substrate bound to unbound enzyme at lower substrate loadings, with substrate saturation occurring at higher loadings (Figure S4). Previous studies have suggested that unbound LPMOs are more susceptible to $\mathrm{H}_{2} \mathrm{O}_{2}$ inactivation; however, as we detail in the Protein Oxidation Measurements section, LPMO inactivation is most likely not occurring in our system. Another possible explanation is that at lower substrate loadings there is a less productive usage of the $\mathrm{H}_{2} \mathrm{O}_{2}$ present in the system. $\mathrm{H}_{2} \mathrm{O}_{2}$ can react rapidly with ascorbic acid leading to a depletion of reductant and, consequentially, lower levels of product formation per molecule of $\mathrm{H}_{2} \mathrm{O}_{2} .{ }^{32}$

Time-Resolved Cellulose Oxidation Measurements Reveal Limitations of the Light-Driven System. As previously discussed, we observed equal levels of PASC oxidation after $3 \mathrm{~h}$ with constant light and intermittent light (Figure 1). However, endpoint determination of light-driven LPMO catalysis does not necessarily allow identification of the limiting factors of the light-driven LPMO reaction. Therefore, we investigated cellulose oxidation at earlier stages during incubation and in time-resolved measurements over a $5 \mathrm{~h}$ period. PASC is widely used as a cellulosic model substrate; however, its less recalcitrant nature differs substantially from the native cellulose structure. Therefore, in the following experiments, we applied cellulose nanofibrils (CNF) comprising fibrillary structures with crystalline and amorphous regions intact. ${ }^{33}$ Due to its colloidal properties, the aqueous suspension of CNF has high optical transparency.

The oxidation of CNF showed a rapid increase in GlcA with constant illumination within the first $30 \mathrm{~min}\left(56 \mathrm{mg} \mathrm{L}^{-1}\right)$ which remained unchanged throughout the course of the experiment (Figure 3). In comparison, after $30 \mathrm{~min}$, the

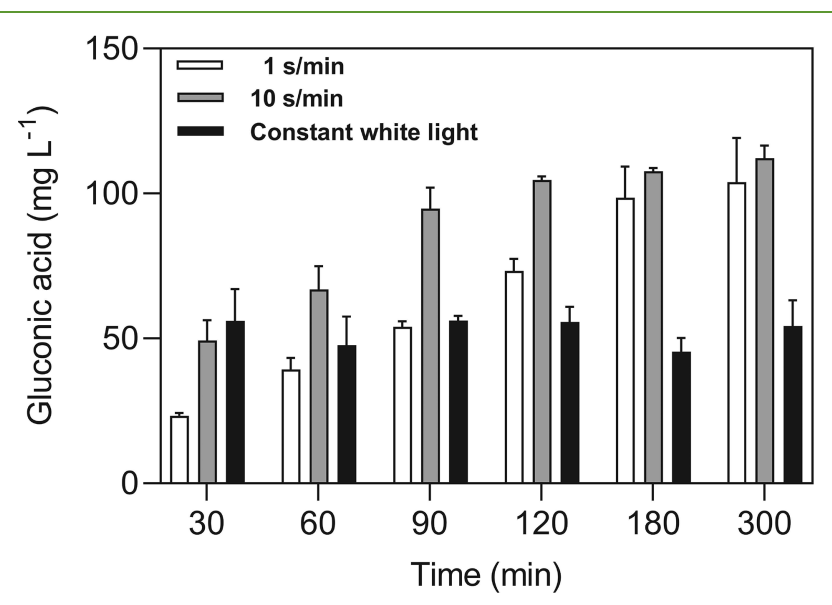

Figure 3. Time-resolved oxidation of cellulose nanofibrils by lightdriven LPMO catalysis. Here, $0.25 \%(\mathrm{w} / \mathrm{v})$ cellulose nanofibrils were incubated for $5 \mathrm{~h}$ under standard conditions $(0.8 \mathrm{mM}$ chlorophyllin, 2 $\mathrm{mM}$ ascorbic acid, $2 \mu \mathrm{M}$ TtAA9, in $100 \mathrm{mM}$ citrate buffer ( $\mathrm{pH} 6.0$ ), $200 \mu \mathrm{mol}$ photons $\mathrm{m}^{-2} \mathrm{~s}^{-1}, 50{ }^{\circ} \mathrm{C}$, and $600 \mathrm{rpm}$ ). Illumination was constant (black), $10 \mathrm{~s}$ light $\min ^{-1}$ (dark gray), or $1 \mathrm{~s} \mathrm{light} \mathrm{min}^{-1}$ (white). Error bars represent the standard deviation of three replicates.

incubations with intermittent illumination reached $23 \mathrm{mg} \mathrm{L}^{-1}$ $(1 \mathrm{~s} / \mathrm{min})$ and $49 \mathrm{mg} \mathrm{L}^{-1}(10 \mathrm{~s} / \mathrm{min})$. The difference between constant illumination and $10 \mathrm{~s} / \mathrm{min}$ after $30 \mathrm{~min}$ of incubation was not significant. Subsequently, levels of GlcA under intermittent light illumination continuously increased with the $10 \mathrm{~s} / \mathrm{min}$ cycle surpassing constant illumination after 60 $\mathrm{min}$ and the $1 \mathrm{~s} / \mathrm{min}$ cycle after $90 \mathrm{~min}$. The $10 \mathrm{~s} / \mathrm{min}$ illumination cycle reached a plateau after $120 \mathrm{~min}$ with twice as much GlcA as with constant illumination. The $1 \mathrm{~s} / \mathrm{min}$ illumination cycle reached levels of GlcA comparable to the 10 s/min cycle after $180 \mathrm{~min}$, with $99 \mathrm{mg} \mathrm{L}^{-1} \mathrm{GlcA}$, and with no significant increase in the remaining $2 \mathrm{~h}$.

The results show that with constant illumination the majority of products are formed within the first $30 \mathrm{~min}$, thus suggesting a limitation of the light-driven LPMO system when constant illumination is applied. Meanwhile, almost equal amounts of GlcA were formed with a 6-fold reduced illumination time $(10 \mathrm{~s} / \mathrm{min})$ after $30 \mathrm{~min}$. Overall, the total amount of GlcA formed under intermittent illumination was 2fold higher than under constant illumination. Therefore, it is unlikely that substrate limitation can explain the early termination of the reaction with constant light. An alternative explanation arises if one interprets the LPMO activity as being $\mathrm{H}_{2} \mathrm{O}_{2}$ dependent. Lower light intensities will naturally lead to less $\mathrm{H}_{2} \mathrm{O}_{2}$ formation and, thus, a slower reaction. However, as 
discussed above, this would have the benefit of conserving the pool of reductant in the system, allowing for a reaction with an improved catalytic lifetime. To address this hypothesis, we proceeded to investigate the oxygen consumption and $\mathrm{H}_{2} \mathrm{O}_{2}$ formation in the light-driven LPMO system.

Oxygen Consumption and Hydrogen Peroxide Formation. $\mathrm{H}_{2} \mathrm{O}_{2}$ has been shown to inactivate LPMOs ${ }^{14}$ and is known to be formed by photoexcited chlorophyllin. ${ }^{34,35}$ Therefore, in order to understand the impact of $\mathrm{H}_{2} \mathrm{O}_{2}$ formation in this light-driven system, we quantified $\mathrm{H}_{2} \mathrm{O}_{2}$ production. First, $\mathrm{O}_{2}$ consumption was measured with intermittent $(10 \mathrm{~s} / \mathrm{min})$ and constant illumination (Figure 4). As expected, intermittent illumination $(10 \mathrm{~s} / \mathrm{min})$ reduced the $\mathrm{O}_{2}$ consumption rates as compared to constant light exposure (Figure 4A). In order to assess how much $\mathrm{O}_{2}$ is converted to $\mathrm{H}_{2} \mathrm{O}_{2}$, we performed a catalase-coupled oxygen
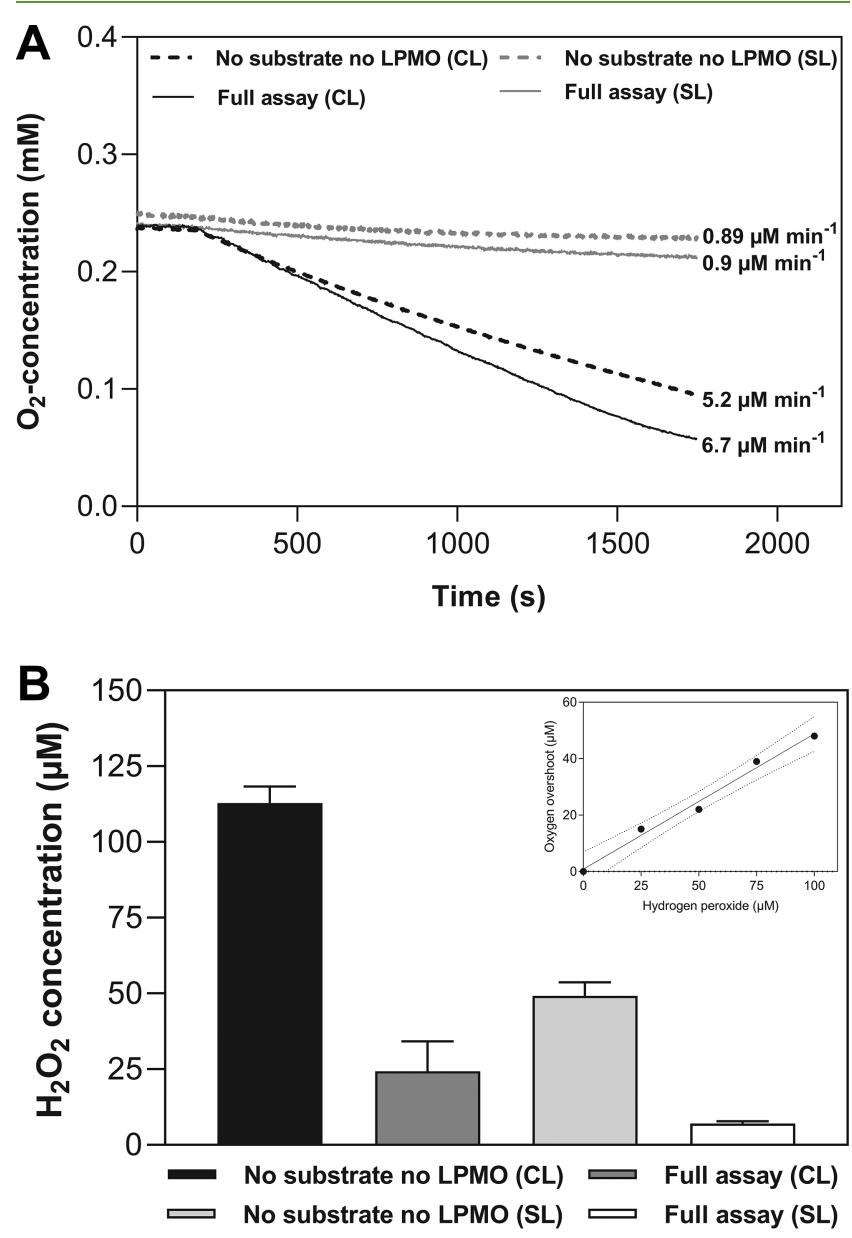

Figure 4. Quantification of free hydrogen peroxide in light-driven LPMO catalysis. Samples were incubated in a closed oxygen chamber with constant $(\mathrm{CL})$ or intermittent light $(10 \mathrm{~s} / \mathrm{min}$; SL) and a light intensity of $200 \mu \mathrm{mol}$ photons $\mathrm{m}^{-2} \mathrm{~s}^{-1}(625 \mathrm{~nm})$. (A) Oxygen consumption rate monitored for $30 \mathrm{~min}$. (B) Quantification of free $\mathrm{H}_{2} \mathrm{O}_{2}$ in the system, determined by measuring the amount of released oxygen upon addition of catalase $\left(3.2 \mu \mathrm{g} \mathrm{mL}{ }^{-1}\right)$ after $30 \mathrm{~min}$ incubation. As shown in the inset in panel (B), the free hydrogen peroxide concentration present in the system showed a linear relationship to the released oxygen after addition of catalase (standard curve with $95 \%$ confidence intervals, $\mathrm{R}^{2}=0.9871$ ). Full assay includes $0.8 \mathrm{mM}$ chlorophyllin, $2 \mathrm{mM}$ ascorbic acid, $0.5 \%$ PASC, and $2 \mu \mathrm{M}$ TtAA9 in $100 \mathrm{mM}$ citrate buffer ( $\mathrm{pH}$ 6.0). "No substrate no LPMO" has the same composition but omits substrate and LPMO. evolution assay to quantify free $\mathrm{H}_{2} \mathrm{O}_{2}$. After 30 min incubation in the oxygen chamber and upon addition of catalase, the $\mathrm{O}_{2}$ evolution was detected and compared to the overshoot in $\mathrm{H}_{2} \mathrm{O}_{2}$ standard solutions. The $\mathrm{O}_{2}$ overshoot and the amount of $\mathrm{H}_{2} \mathrm{O}_{2}$ showed a linear correlation (Figure $4 \mathrm{~B}$ inset); therefore, this setup was used to estimate $\mathrm{H}_{2} \mathrm{O}_{2}$ generation in the lightdriven LPMO system. After $30 \mathrm{~min}$ of constant illumination, the $\mathrm{H}_{2} \mathrm{O}_{2}$ concentration was approximately $113 \mu \mathrm{M}$ (no substrate, no LPMO) and $24 \mu \mathrm{M}$ (full assay). After $30 \mathrm{~min}$ under a $10 \mathrm{~s} / \mathrm{min}$ illumination cycle, the concentration was lower in both conditions ( 49 and $7 \mu \mathrm{M}$, respectively). These results suggest that in the absence of LPMO and substrate $\mathrm{H}_{2} \mathrm{O}_{2}$ is formed efficiently via an interaction between the photosensitizer and the reductant and accumulates in the system. The lower levels of $\mathrm{H}_{2} \mathrm{O}_{2}$ in the presence of LPMO and substrate indicate enzymatic consumption of $\mathrm{H}_{2} \mathrm{O}_{2}$ that drives the reaction which is in contrast to previous findings. ${ }^{35}$ The difference in consumption rates between constant illumination and the $10 \mathrm{~s} / \mathrm{min}$ illumination cycle suggests that in constant illumination there could be an additional, nonproductive, $\mathrm{H}_{2} \mathrm{O}_{2}$ sink. As discussed above, when in excess, $\mathrm{H}_{2} \mathrm{O}_{2}$ can be deleterious to the reactions by inactivating the enzyme or depleting the pool of reductant. To address these possibilities, we first quantified enzyme oxidation under our reaction conditions.

Protein Oxidation Measurements Do Not Suggest Substantial Oxidative Damage. In continuation of the previous experiments, we measured oxidation of TtAA9 to evaluate the degree of putative inactivation due to oxidative modifications of amino acids and whether such modifications could explain the cessation of cellulose oxidation after $30 \mathrm{~min}$. To this end, samples containing LPMO, ascorbic acid, and chlorophyllin were incubated for $30 \mathrm{~min}$ with and without substrate under constant and intermittent illumination, and protein oxidation was subsequently measured by mass spectrometry.

TtAA9 contains four histidine residues with three of these in proximity to the copper-active site and one near the protein surface (Figure 5A). It has previously been shown that the histidine residues at the copper-active site are hotspots for oxidative modifications when interacting with $\mathrm{H}_{2} \mathrm{O}_{2}{ }^{14}$ However, when compared to nonincubated enzyme controls, we were unable to detect any significant difference in histidine oxidation, or any other amino acid analyzed, after $30 \mathrm{~min}$ incubation under constant, $10 \mathrm{~s} / \mathrm{min}$, or $1 \mathrm{~s} / \mathrm{min}$ illumination (Figure 5B and Figure S5). While oxidative damage to LPMOs may occur over the long term and hence decreases catalytic efficiency via enzyme inactivation, this does not seem to be a significant process over the time frame of the experiments conducted in this study, and oxidative enzyme inactivation does not appear to account for the cessation of substrate oxidation. These results are in contrast with recent work on AA10 LPMOs where the enzyme is rapidly inactivated in the present of excess $\mathrm{H}_{2} \mathrm{O}_{2}{ }^{13,14}$ An explanation could be that, upon the addition of $\mathrm{H}_{2} \mathrm{O}_{2}$, AA9 LPMOs form a $\mathrm{Cu}$ (II)-tyrosyl radical $^{21,22}$ which protects the active site from inactivation via pathways described in previous reports. ${ }^{36,37}$ However, in AA10 LPMOs, the noncoordinating amino acid residue near the active site is primarily a phenylalanine; ${ }^{38}$ therefore, this protective mechanism may be absent.

Reductant Depletion Is the Most Likely Cause for Early Cessation of Oxidation. As reported above, neither substrate limitation nor protein oxidation appears, per se, to be 
(A)

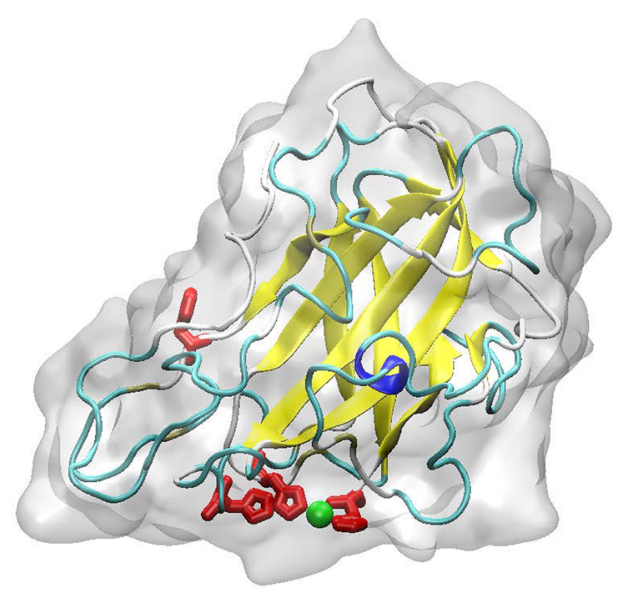

(B)

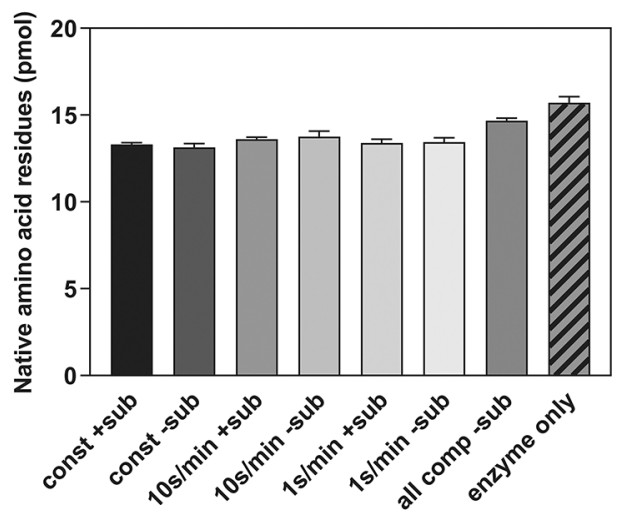

Figure 5. Depiction and oxidative modification of histidine residues in TtAA9. (A) TtAA9 protein structures with highlighted histidine residues (red) and monocopper in the active site (green). (B) Oxidative modifications of the histidine residues incubated under standard conditions ( $0.8 \mathrm{mM}$ chlorophyllin, $2 \mathrm{mM}$ ascorbic acid, 2 $\mu \mathrm{M}$ TtAA9, in $100 \mathrm{mM}$ citrate buffer ( $\mathrm{pH} 6.0$ ), $200 \mu$ mol photons $\mathrm{m}^{-2} \mathrm{~s}^{-1}, 50{ }^{\circ} \mathrm{C}$, and $\left.600 \mathrm{rpm}\right)$ with (+sub) and without substrate (-sub) $(0.25 \% \mathrm{CNF} w / \mathrm{v})$ for $30 \mathrm{~min}$ and with different illumination cycles as indicated $(1 \mathrm{~s} / \mathrm{min}, 10 \mathrm{~s} / \mathrm{min}$, and constant light). Histidine oxidation would appear as a reduction in native histidine content, measured in pmol. Enzyme only refers to a control directly measured from the used enzyme stock. All comp-sub refers to an enzyme control to which all assay components except the substrate were added, but the sample was not incubated. The structures were drawn from 2yet.pdb, using VMD 1.9.3. ${ }^{40}$

responsible for the cessation of cellulose oxidation after $30 \mathrm{~min}$ under constant illumination. Therefore, limitations arising from depletion of the reductant pool or the loss of photosensitizer due to photobleaching were examined. Chlorophyllin absorption spectra before and after light-driven LPMO catalysis showed no detectable changes (Figure S6), which suggests that photobleaching does not limit the reaction as corroborated by the experiments with additional ascorbic acid.

As ascorbic acid, used as a reductant in our system, can take part in several reactions in this complex redox-active system (e.g., reduction of the oxidized photosensitizer after electron donation, quenching of the triplet state of the photosensitizer, reduction of the $\mathrm{Cu}$-active site to $\mathrm{Cu}-(\mathrm{I})$, formation and scavenging of $\mathrm{H}_{2} \mathrm{O}_{2}$, and self-oxidation), ${ }^{39}$ depletion is a plausible factor in limiting cellulose oxidation.

To test this hypothesis, we added additional ascorbic acid throughout experiments with constant illumination. These experiments also employed a 2 -fold increase in substrate loading in order to avoid any substrate related limitations. At a $2 \mathrm{mM}$ reductant concentration, the yield of GlcA was the same for 30 and $60 \mathrm{~min}$ reactions (Figure 6, c.f. Figure 3). Adding an

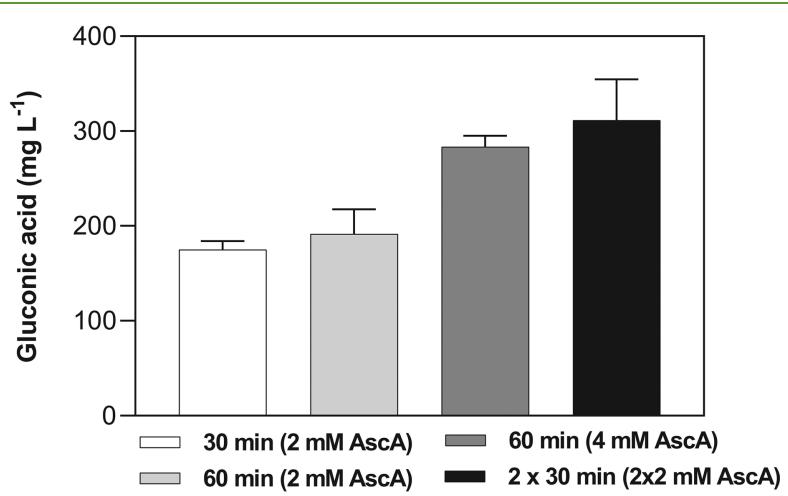

Figure 6. Reductant addition experiments for the oxidation of cellulose nanofibrils (CNF). Cellulose nanofibers $(0.5 \% \mathrm{w} / \mathrm{v})$ were incubated under standard conditions $(0.8 \mathrm{mM}$ chlorophyllin, $2 \mathrm{mM}$ ascorbic acid, $2 \mu \mathrm{M}$ TtAA9, in $100 \mathrm{mM}$ citrate buffer (pH 6.0), 200 $\mu$ mol photons $\mathrm{m}^{-2} \mathrm{~s}^{-1}, 50{ }^{\circ} \mathrm{C}$, and $600 \mathrm{rpm}$ ) with varying ascorbic acid (AscA) concentrations and incubation times. Here, $2 \mathrm{mM}$ AscA/ $30 \mathrm{~min}$ (white), $2 \mathrm{mM}$ AscA/60 min (light gray), $4 \mathrm{mM} \mathrm{AscA} / 60 \mathrm{~min}$ (dark gray), and $2 \times 2 \mathrm{mM} \mathrm{AscA} / 30 \mathrm{~min}$ (black). Error bars represent the standard deviation of three replicates.

additional $2 \mathrm{mM}$ reductant after $30 \mathrm{~min}$ resulted in a significantly higher GlcA level at $60 \mathrm{~min}$, indicating that indeed the reductant is limiting the reaction. This was confirmed by a $60 \mathrm{~min}$ assay with a one-time addition of a 4 $\mathrm{mM}$ reductant. Altogether, these data suggest it is likely that the excess of $\mathrm{H}_{2} \mathrm{O}_{2}$ produced in constant illumination (Figure $4 \mathrm{~A}$ ) is rapidly depleting the pool of reductants, and this can be alleviated by using an intermittent illumination.

\section{CONCLUSIONS}

Applying intermittent on/off illumination provides a means to enhance LPMO photobiocatalysis with decreased energy input. Importantly, characterization of the intermittent illumination system demonstrated that the advantage is highest at relatively low substrate loadings. Time-resolved measurements revealed that the initial rate of cellulose oxidation was greater during constant illumination as compared to the $1 \mathrm{~s} / \mathrm{min}$ cycle, but the difference was not significant compared to a 6-fold reduced illumination time $(10 \mathrm{~s} / \mathrm{min}$ cycle). However, the increased initial rate of oxidation was not sustained, and the product yield at later time points was higher with intermittent illumination due to a cessation of product generation after the first $30 \mathrm{~min}$ of incubation in constant illumination. Substrate limitation was excluded as a potential cause of the termination of activity by comparing the constant (GlcA plateau after $30 \mathrm{~min}$ ) with intermittent light (higher GlcA concentrations after 90 and $120 \mathrm{~min}$ ). In addition, there were no significant oxidative modifications detected on the LPMO after $30 \mathrm{~min}$ of incubation. Instead, we show that light-driven LPMO catalysis ceases because of reductant depletion which likely occurs due to a reaction with excess $\mathrm{H}_{2} \mathrm{O}_{2}$ in the system. Overall, this underlines the importance of optimizing the illumination process in photobiocatalytic LPMO systems to balance the beneficial and detrimental effects of $\mathrm{H}_{2} \mathrm{O}_{2} .{ }^{13}$ This can conserve the pool of necessary reductants and extend the 
lifetime of LPMO-driven cellulose oxidation. It should be noted that the substrates tested here are not lignocellulosic substrates. Lignin-rich substrates contain intrinsic reducing power that will complicate the redox relationships in this system. ${ }^{32}$ Therefore, further optimization will be needed to move toward industrial application.

Nevertheless, these findings have important implications for the development of continuous photobioreactor systems, as they show a trade-off between the rate of LPMO catalysis and depletion of reductant dependent on illumination time. Ideally, reductants would be identified that are less prone to nonproductive light-driven depletion. Additionally, these reductants would preferentially be naturally available, small molecule, electron donors, such as low-molecular weight lignins. Furthermore, many relevant substrates scatter (and absorb) light strongly, such that even continuous illumination effectively results in intermittent light exposure due to fluctuating internal shading within a photobioreactor and nonproductive light absorption by other molecules than the photosensitizers. Our observation that intermittent illumination can perform equally well or better than continuous light is therefore crucial for such applications. It is furthermore interesting to consider the use of a substrate circulation loop, illuminated by either natural sunlight or LEDs powered by renewable electricity, as a source of light for current biomass reactors. This could be of particular value for substrates with a higher degree of transparency or for photobiocatalytic systems utilizing soluble substrates. Further experimental work will be required to test the feasibility of such an approach and to investigate whether or not light-driven LPMOs can be applied to depolymerize lignocellulosic biomass.

\section{ASSOCIATED CONTENT}

\section{SI Supporting Information}

The Supporting Information is available free of charge at https://pubs.acs.org/doi/10.1021/acssuschemeng.0c00702.

Spectral range of white-light LEDs, TtAA9 enzyme reduction experiment, light transmittance with increased concentration of microcrystalline cellulose, LPMO binding with increasing concentrations of microcrystalline cellulose, determination of oxidative modifications of amino acid residues other than His, and absorption spectroscopy of chlorophyllin before and after illumination with constant light. (PDF)

\section{AUTHOR INFORMATION}

\section{Corresponding Authors}

Benedikt M. Blossom - Department of Geosciences and Natural Resource Management, University of Copenhagen, 1958 Frederiksberg, Denmark; 이이이.org/0000-0002-83266140; Email: kbm@ign.ku.dk

Claus Felby - Department of Geosciences and Natural Resource Management, University of Copenhagen, 1958 Frederiksberg, Denmark; Email: cf@ign.ku.dk

\section{Authors}

David A. Russo - Department of Plant and Environmental Sciences, University of Copenhagen, 1871 Frederiksberg, Denmark

Raushan K. Singh - Department of Chemistry, University of Copenhagen, 2100 Copenhagen, Denmark
Bart van Oort - Department of Physics and Astronomy, Vrije Universiteit Amsterdam, 1081 Amsterdam, Netherlands

Malene B. Keller - Department of Geosciences and Natural Resource Management, University of Copenhagen, 1958 Frederiksberg, Denmark

Tor I. Simonsen - Department of Geosciences and Natural Resource Management, University of Copenhagen, 1958 Frederiksberg, Denmark

Alixander Perzon - Department of Plant and Environmental Sciences, University of Copenhagen, 1871 Frederiksberg, Denmark; (1) orcid.org/0000-0002-1430-2961

Luke F. Gamon - Department of Biomedical Sciences, University of Copenhagen, 2200 Copenhagen, Denmark

Michael J. Davies - Department of Biomedical Sciences, University of Copenhagen, 2200 Copenhagen, Denmark; (1) orcid.org/0000-0002-5196-6919

David Cannella - École interfacultaire de Bioingénieurs, Universite Libre de Bruxelles, 1050 Brussels, Belgium

Roberta Croce - Department of Physics and Astronomy, Vrije Universiteit Amsterdam, 1081 Amsterdam, Netherlands; (1) orcid.org/0000-0003-3469-834X

Poul Erik Jensen - Department of Plant and Environmental Sciences, University of Copenhagen, 1871 Frederiksberg, Denmark; 이이이.org/0000-0001-6524-7723

Morten J. Bjerrum - Department of Chemistry, University of

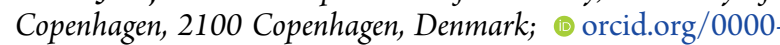
0002-8410-627X

Complete contact information is available at:

https://pubs.acs.org/10.1021/acssuschemeng.0c00702

\section{Author Contributions}

B.M.B. and C.F. conceptualized the study with contributions from D.C. B.M.B. designed and performed the experiments and analyzed the data with contributions from D.A.R., B.v.O., and C.F. R.K.S. prepared the purified and copper loaded TtAA9. A.P. prepared the CNF. M.B.K. performed LPMO binding experiments. T.I.S. performed oxygen measurements. L.F.G. and M.J.D. performed LPMO oxidation measurements. R.K.S., M.B.K., T.I.S., L.F.G., M.J.D., R.C., M.J.B., and P.E.J. assisted in experimental design and data analysis. B.M.B. drafted the manuscript with contributions from all authors. All authors have read and approved the final manuscript.

\section{Notes}

The authors declare no competing financial interest.

\section{ACKNOWLEDGMENTS}

The authors would like to sincerely thank Anne Stenbæk and, in particular, Johan Pelck Olsen from Novozymes A/S for their support and supply of enzyme as well as KMC for providing potato pulp. This work was funded by the Novo Nordisk Foundation (Grant NNF16OC0021832 and NNF13OC0004294), the Innovation Fund Denmark (Grants 7043-00016B and 5152-00001B).

\section{REFERENCES}

(1) Schmermund, L.; Jurkaš, V.; Özgen, F. F.; Barone, G. D.; Büchsenschütz, H. C.; Winkler, C. K.; Schmidt, S.; Kourist, R.; Kroutil, W. Photo-biocatalysis: Biotransformations in the presence of light. ACS Catal. 2019, 9 (5), 4115-4144.

(2) Lee, S. H.; Choi, D. S.; Kuk, S. K.; Park, C. B. Photobiocatalysis: Activating redox enzymes by direct or indirect transfer of photoinduced electrons. Angew. Chem., Int. Ed. 2018, 57 (27), 7958-7985. 
(3) Simaan, A. J.; Mekmouche, Y.; Herrero, C.; Moreno, P.; Aukauloo, A.; Delaire, J. A.; Réglier, M.; Tron, T. Photoinduced multielectron transfer to a multicopper oxidase resulting in dioxygen reduction into water. Chem. - Eur. J. 2011, 17 (42), 11743-11746.

(4) Ener, M. E.; Lee, Y.-T.; Winkler, J. R.; Gray, H. B.; Cheruzel, L. Photooxidation of cytochrome P450-BM3. Proc. Natl. Acad. Sci. U. S. A. 2010, 107 (44), 18783-18786.

(5) Tran, N.-H.; Nguyen, D.; Dwaraknath, S.; Mahadevan, S.; Chavez, G.; Nguyen, A.; Dao, T.; Mullen, S.; Nguyen, T.-A.; Cheruzel, L. E. An efficient light-driven P450 BM3 biocatalyst. J. Am. Chem. Soc. 2013, 135 (39), 14484-14487.

(6) Jensen, K.; Jensen, P. E.; Møller, B. L. Light-Driven Cytochrome P450 Hydroxylations. ACS Chem. Biol. 2011, 6 (6), 533-539.

(7) Quinlan, R. J.; Sweeney, M. D.; Lo Leggio, L.; Otten, H.; Poulsen, J.-C. N.; Johansen, K. S.; Krogh, K. B. R. M.; Jorgensen, C. I.; Tovborg, M.; Anthonsen, A.; Tryfona, T.; Walter, C. P.; Dupree, P.; Xu, F.; Davies, G. J.; Walton, P. H. Insights into the oxidative degradation of cellulose by a copper metalloenzyme that exploits biomass components. Proc. Natl. Acad. Sci. U. S. A. 2011, 108 (37), 15079-15084.

(8) Aachmann, F. L.; Sørlie, M.; Skjåk-Bræk, G.; Eijsink, V. G.; Vaaje-Kolstad, G. NMR structure of a lytic polysaccharide monooxygenase provides insight into copper binding, protein dynamics, and substrate interactions. Proc. Natl. Acad. Sci. U. S. A. 2012, 109 (46), 18779-18784.

(9) Ciano, L.; Davies, G. J.; Tolman, W. B.; Walton, P. H. Bracing copper for the catalytic oxidation of $\mathrm{C}-\mathrm{H}$ bonds. Nature Catalysis 2018, 1 (8), 571-577.

(10) Hemsworth, G. R.; Taylor, E. J.; Kim, R. Q.; Gregory, R. C.; Lewis, S. J.; Turkenburg, J. P.; Parkin, A.; Davies, G. J.; Walton, P. H. The copper active site of CBM33 polysaccharide oxygenases. J. Am. Chem. Soc. 2013, 135 (16), 6069-6077.

(11) Cannella, D.; Möllers, K. B.; Frigaard, N.-U.; Jensen, P. E.; Bjerrum, M. J.; Johansen, K. S.; Felby, C. Light-driven oxidation of polysaccharides by photosynthetic pigments and a metalloenzyme. Nat. Commun. 2016, 7 (1), 1-8.

(12) Bissaro, B.; Forsberg, Z.; Ni, Y.; Hollmann, F.; Vaaje-Kolstad, G.; Eijsink, V. G. H. Fueling biomass-degrading oxidative enzymes by light-driven water oxidation. Green Chem. 2016, 18 (19), 5357-5366.

(13) Bissaro, B.; Kommedal, E.; Røhr, Å. K.; Eijsink, V. G. H. Controlled depolymerization of cellulose by light-driven lytic polysaccharide oxygenases. Nat. Commun. 2020, 11 (1), 890.

(14) Bissaro, B.; Røhr, Å. K.; Müller, G.; Chylenski, P.; Skaugen, M.; Forsberg, Z.; Horn, S. J.; Vaaje-Kolstad, G.; Eijsink, V. G. H. Oxidative cleavage of polysaccharides by monocopper enzymes depends on $\mathrm{H} 2 \mathrm{O} 2$. Nat. Chem. Biol. 2017, 13, 1123.

(15) Vaaje-Kolstad, G.; Westereng, B.; Horn, S. J.; Liu, Z.; Zhai, H.; Sørlie, M.; Eijsink, V. G. An oxidative enzyme boosting the enzymatic conversion of recalcitrant polysaccharides. Science 2010, 330 (6001), 219-222.

(16) Horn, S. J.; Vaaje-Kolstad, G.; Westereng, B.; Eijsink, V. G. Novel enzymes for the degradation of cellulose. Biotechnol. Biofuels 2012, 5 (1), 45 .

(17) Isaksen, T.; Westereng, B.; Aachmann, F. L.; Agger, J. W.; Kracher, D.; Kittl, R.; Ludwig, R.; Haltrich, D.; Eijsink, V. G.; Horn, S. $\mathrm{J}$. A C4-oxidizing lytic polysaccharide monooxygenase cleaving both cellulose and cello-oligosaccharides. J. Biol. Chem. 2014, 289 (5), $2632-2642$.

(18) Hemsworth, G. R.; Johnston, E. M.; Davies, G. J.; Walton, P. H. Lytic Polysaccharide Monooxygenases in Biomass Conversion. Trends Biotechnol. 2015, 33 (12), 747-761.

(19) Walton, P. H.; Davies, G. J. On the catalytic mechanisms of lytic polysaccharide monooxygenases. Curr. Opin. Chem. Biol. 2016, 31, 195-207.

(20) Beeson, W. T.; Vu, V. V.; Span, E. A.; Phillips, C. M.; Marletta, M. A. Cellulose degradation by polysaccharide monooxygenases. Annu. Rev. Biochem. 2015, 84, 923-946.

(21) Singh, R. K.; Blossom, B. M.; Russo, D. A.; Singh, R.; Weihe, H.; Andersen, N. H.; Tiwari, M. K.; Jensen, P. E.; Felby, C.; Bjerrum,
M. J. Detection and Characterization of a Novel Copper-Dependent Intermediate in a Lytic Polysaccharide Monooxygenase. Chem. - Eur. J. 2020, 26 (2), 454-463.

(22) Paradisi, A.; Johnston, E. M.; Tovborg, M.; Nicoll, C. R.; Ciano, L.; Dowle, A.; McMaster, J.; Hancock, Y.; Davies, G. J.; Walton, P. H. Formation of a Copper(II)-Tyrosyl Complex at the Active Site of Lytic Polysaccharide Monooxygenases Following Oxidation by $\mathrm{H} 2 \mathrm{O} 2$. J. Am. Chem. Soc. 2019, 141 (46), 18585-18599.

(23) Kittl, R.; Kracher, D.; Burgstaller, D.; Haltrich, D.; Ludwig, R. Production of four Neurospora crassa lytic polysaccharide monooxygenases in Pichia pastoris monitored by a fluorimetric assay. Biotechnol. Biofuels 2012, 5 (1), 79.

(24) Kracher, D.; Scheiblbrandner, S.; Felice, A. K.; Breslmayr, E.; Preims, M.; Ludwicka, K.; Haltrich, D.; Eijsink, V. G.; Ludwig, R. Extracellular electron transfer systems fuel cellulose oxidative degradation. Science 2016, 352 (6289), 1098-1101.

(25) Frommhagen, M.; Westphal, A. H.; van Berkel, W. J. H.; Kabel, M. A. Distinct Substrate Specificities and Electron-Donating Systems of Fungal Lytic Polysaccharide Monooxygenases. Front. Microbiol. 2018, 9 (1080), na DOI: 10.3389/fmicb.2018.01080.

(26) Russo, D. A.; Zedler, J. A. Z.; Jensen, P. E. A force awakens: exploiting solar energy beyond photosynthesis. J. Exp. Bot. 2019, 70 (6), 1703-1710.

(27) Pace, C. N.; Vajdos, F.; Fee, L.; Grimsley, G.; Gray, T. How to measure and predict the molar absorption coefficient of a protein. Protein Sci. 1995, 4 (11), 2411-2423.

(28) Wood, T. M. Preparation of crystalline, amorphous, and dyed cellulase substrates. In Methods in Enzymology; Academic Press: 1988; Vol. 160, pp 19-25.

(29) Keller, M.; Felby, C.; Labate, C.; Pellegrini, V.; Higasi, P.; Singh, R.; Polikarpov, I.; Blossom, B. A simple enzymatic assay for the quantification of $\mathrm{C} 1$-specific cellulose oxidation by lytic polysaccharide monooxygenases. Biotechnol. Lett. 2020, 42 (1), 93-102.

(30) Westereng, B.; Agger, J. W.; Horn, S. J.; Vaaje-Kolstad, G.; Aachmann, F. L.; Stenstrøm, Y. H.; Eijsink, V. G. Efficient separation of oxidized cello-oligosaccharides generated by cellulose degrading lytic polysaccharide monooxygenases. Journal of Chromatography $A$ 2013, 1271 (1), 144-152.

(31) Green, J. W.; Thompson, N. S.; Pearl, I. A.; Swanson, J. W. Study of the Carbohydrate Peeling and Stopping Reactions under the Conditions of Oxygen-Alkali Pulping; Project 3265, Report 2: A Progress Report to Members of the Institute of Paper Chemistry, 1976.

(32) Müller, G.; Chylenski, P.; Bissaro, B.; Eijsink, V. G. H.; Horn, S. $\mathrm{J}$. The impact of hydrogen peroxide supply on LPMO activity and overall saccharification efficiency of a commercial cellulase cocktail. Biotechnol. Biofuels 2018, 11 (1), 209.

(33) Klemm, D.; Kramer, F.; Moritz, S.; Lindström, T.; Ankerfors, M.; Gray, D.; Dorris, A. Nanocelluloses: a new family of nature-based materials. Angew. Chem., Int. Ed. 2011, 50 (24), 5438-5466.

(34) Itoh, T.; Ishii, A.; Kodera, Y.; Hiroto, M.; Matsushima, A.; Nishimura, H.; Inada, Y. Chlorophyllin Coupled With Polyethylene Glycol:. a Potent Photosensitizer. Res. Chem. Intermed. 1996, 22 (2), 129-136.

(35) Möllers, K. B.; Mikkelsen, H.; Simonsen, T. I.; Cannella, D.; Johansen, K. S.; Bjerrum, M. J.; Felby, C. On the formation and role of reactive oxygen species in light-driven LPMO oxidation of phosphoric acid swollen cellulose. Carbohydr. Res. 2017, 448, 182186.

(36) Gray, H. B.; Winkler, J. R. Hole hopping through tyrosine/ tryptophan chains protects proteins from oxidative damage. Proc. Natl. Acad. Sci. U. S. A. 2015, 112 (35), 10920-10925.

(37) Winkler, J. R.; Gray, H. B. Could tyrosine and tryptophan serve multiple roles in biological redox processes? Philos. Trans. R. Soc., A 2015, 373 (2037), 20140178.

(38) Book, A. J.; Yennamalli, R. M.; Takasuka, T. E.; Currie, C. R.; Phillips, G. N.; Fox, B. G. Evolution of substrate specificity in bacterial AA10 lytic polysaccharide monooxygenases. Biotechnol. Biofuels 2014, 7 (1), 109. 
(39) Du, J.; Cullen, J. J.; Buettner, G. R. Ascorbic acid: chemistry, biology and the treatment of cancer. Biochim. Biophys. Acta, Rev. Cancer 2012, 1826 (2), 443-457.

(40) Humphrey, W.; Dalke, A.; Schulten, K. VMD: visual molecular dynamics. J. Mol. Graphics 1996, 14 (1), 33-38. 